\title{
O DESENVOLVIMENTO URBANO DEMOCRÁTICO COMO UTOPIA
}

\author{
ENTREVISTA COM ERMÍNIA MARICATO, \\ Secretária Executiva do Ministério das Cidades
}

\author{
Ana Clara Torres Ribeiro ${ }^{1}$ \\ HENRI ACSELRAD
}

RBEUR: Sugerimos começar por alguns temas mais gerais, como a gênese e a construção do Ministério das Cidades, para depois ir afunilando para as politicas.

ERMínIA: Nas últimas vezes em que Lula foi candidato à presidência da República constava, em seu programa de governo, a proposta de criação de um Ministério com os nomes variáveis de Ministério da Reforma Urbana, Ministério do Desenvolvimento Urbano e Ministério das Cidades. Numa dessas oportunidades (se não me engano, na terceira candidatura) foi criado um grupo de expressão nacional, reunindo trabalhadores sindicais, professores universitários e movimentos sociais, que escreveu um programa denominado de Reforma Urbana, impresso pelo partido como parte do Programa de Governo. Lá propúnhamos o Ministério da Reforma Urbana. A proposta de um Ministério da Política Urbana surgiu novamente no Projeto Moradia. Por meio do Instituto Cidadania, Lula convidou um grupo de pessoas (profissionais, lideranças sociais, parlamentares) para elaborar uma proposta de habitação. O Instituto realizou várias audiências para ouvir pessoas de outros segmentos. O documento elaborado por esse grupo mostra que as soluções para a carência habitacional devem ser buscadas no contexto da cidade. Afirmamos assim que era preciso recuperar um espaço de institucionalização da política urbana que tinha sido perdido. Segundo o Projeto Moradia, por meio de um ministério, poderíamos tratar dos três maiores problemas sociais urbanos que, muitas vezes, na discussão dos planos diretores e nos debates urbanísticos não apareciam como centrais: o problema da moradia, em especial da moradia social, o proble-

1 Entrevista concedida em Porto Alegre, em janeiro de 2005. ma do saneamento ambiental, compreendendo água, esgoto, drenagem e lixo, e o problema do transporte coletivo urbano. A proposta do Projeto Moradia aprofundou muito mais a política habitacional e, dentro dela, seus elementos estruturantes: a questão fundiária, a questão do financiamento e a da estrutura institucional necessária. O Ministério das Cidades foi estruturado [em secretarias] a partir das três maiores fontes dos problemas sociais urbanos vinculados ao território: habitação, saneamento ambiental e transporte. A essas somou-se uma quarta secretaria, a de Programas Especiais Urbanos, que tinha como objetos o planejamento e a política fundiária, entre outras atribuições.

RBEUR: No que se refere a essa junção operada entre diferentes fragmentos da máquina pública, nesses dois anos de existência do Ministério, você acha que foi possivel olhar a cidade como objeto de política, ou ainda há resíduos de fragmentação dos instrumentos necessários para um planejamento de longo prazo?

ERMínIA: Essa fragmentação vai continuar por muito tempo, por causa da própria formação universitária e profissional, que é fragmentada. Lembremos do saneamento e dos transportes ou então o fato de os arquitetos e urbanistas olharem muito pouco para esses temas. No Ministério isso é muito visível e estamos obtendo, quanto a isto, muitos ganhos por intermédio do Conselho das Cidades. O Conselho das Cidades tem Câmaras Técnicas separadas. As discussões técnicas precisam de fato de um detalhamento e devem respeitar a necessidade do aprofundamento setorial e da verticalização, mas é preciso também assegurar a integração. As discussões são feitas nas Câmaras Técnicas e depois vão ao plenário do Conselho, o que obriga a todos os seto- 
res das políticas setoriais a dialogar com enfoque transversal. O conceito de mobilidade, que é uma obsessão para nossa equipe da Secretaria Nacional de Transporte e da Mobilidade Urbana, esse olhar - o da relação entre mobilidade, transporte e desenvolvimento urbano - é muito evidente. A mobilidade no território urbano não é dada apenas pelo transporte, mas pelo uso e ocupação do solo. As características de um trânsito desumano e altamente mortal não são vistas apenas pelo viés do veículo, mas especialmente dos pedestres, da falta de infra-estrutura, em especial calçadas, da falta de sinalização, do desenho urbano adequado e, evidentemente, da falta de educação para o trânsito. O Denatran - Departamento Nacional do Trânsito veio do Ministério da Justiça para o Ministério das Cidades. Do Ministério dos Transportes trouxemos duas empresas de trens e metrôs. A Companhia Brasileira de Trens Urbanos está construindo quatro metrôs e tem a coordenação de três sistemas de trens, antigos e sucateados: os metrôs de Fortaleza, Recife, Belo Horizonte e Salvador e os sistemas de trens em Natal, Maceió e João Pessoa. Contamos ainda com uma companhia que está situada em Porto Alegre, que é a Trensurb. A política de saneamento e a de habitação já foram aprovadas no Conselho das Cidades. Foram aprovadas também as diretrizes da Política de Mobilidade Urbana e estamos preparando a Política Nacional de Mobilidade e Transporte Público, o que não é um tema banal: o que cabe ao governo federal nessa área?

RBEUR: E quanto aos quadros e competências? Como têm sido formados ou trazidos os quadros que são portadores das memórias institucionais, setoriais e das especialidades. Como está ocorrendo esta composição, e qual seria a expectativa em termos de profissionais adequados?

ERMínIA: O Ministério, criado em 2003, cresceu e expandiu suas atribuições em relação à Sedu - Secretaria Especial de Desenvolvimento Urbano que o precedeu, mas ainda é um organismo extremamente enxuto e sem funcionários de carreira. Estamos trabalhando com muita dificuldade em razão disso. As tarefas têm sido enormes: além de criar o Ministério física e institucionalmente, executar os programas e ao mesmo tempo reformulá-los, estamos debatendo com a sociedade a formulação de uma nova política nacional de médio e longo prazos. A falta de recursos para a criação de um organismo amplo e regionalizado e a existência da Caixa Econômica Federal, que tem grande capilaridade, levou à opção por não termos sedes regionais. Alguns ministérios têm representação regional. A Caixa Econômica Federal é operadora dos programas do Ministério, com recursos do OGU - Orçamento Geral da União, e além de operadora é financiadora quando se trata de recursos do FGTS. A criação do Ministério traz algum impacto sobre a Caixa, e entendemos que vai levar um certo tempo para que se chegue a um pacto sobre procedimentos e encaminhamentos. Vou citar um exemplo paradigmático: aprovar projeto de conjuntos habitacionais fora da rede urbana existente como desejamos é algo que ainda estamos longe de atingir. Entendemos que precisamos de muito entendimento e esforço de capacitação para que consigamos disseminar as idéias do direito à cidade assim como o direito à arquitetura. E não se trata apenas de pessoal de ponta da Caixa Econômica que precisa ser preparado para o direito à cidade, são os projetistas, são as prefeituras, são as universidades. A capacitação de pessoal é tão ou mais estratégica do que a ampliação dos recursos. Os secretários nacionais foram indicados de forma democrática com forte acento dos movimentos sociais e também das corporações profissionais - o Secretário de Transporte e da Mobilidade Urbana, José Carlos Xavier, por exemplo, compôs uma lista tríplice com a participação do setorial de transportes do PT e companheiros da ANTP - Associação Nacional de Transportes Públicos; a Frente Nacional do Saneamento indicou também alguns companheiros e o ministro escolheu, da lista que eles indicaram para a Secretaria Nacional de Saneamento Ambiental, um sindicalista, Abelardo de Oliveira Filho, antigo e respeitado militante da área, com grande conhecimento técnico. $\mathrm{O}$ secretário de Habitação veio com o apoio dos movimentos de moradia. Ele passou pela Cohab de Salvador e de São Paulo, pelas prefeituras de Diadema e de Ribeirão Pires, tendo sido um dos pioneiros da Articulação Nacional do Solo Urbano criada pela Comissão Pastoral da Terra na década de 1980. A urbanista Raquel Rolnik, secretária nacional de Programas Urbanos, que dispensa apresentação, foi indicada ao ministro pelo Fórum Nacional de Reforma Urbana. O presidente do Denatran também foi indicado por diversas fontes pela sua extensa experiência administrativa com o assunto. Eu fui convidada, já no período de 
transição de governo, pelo presidente Lula, para participar do desenho do Ministério, a partir da experiência que tivemos durante a elaboração do Projeto Moradia, e depois acabei ficando na Secretaria Executiva a convite do ministro Olívio Dutra, que trouxe da sua equipe anterior do governo do Rio Grande do Sul um pequeno número de colaboradores, entre eles o Dirceu Lopes, chefe de gabinete, e a Íria Charão, secretária executiva do Conselho das Cidades. A indicação de nomes pelos respectivos setores de atuação, profissional ou militante, gerou algumas críticas, assim como o fato de a maior parte dos quadros da equipe do Ministério virem do PT. Os nomes foram indicados por movimentos sociais que na verdade estão na origem de diversas conquistas relativas à democratização da questão urbana a Constituição Federal de 88, os orçamentos participativos, o Projeto de Lei (PL) do Fundo Nacional de Habitação de Interesse Social, o Estatuto da Cidade, e como seguimento dessa relação está também a criação do Ministério das Cidades com a Conferência Nacional das Cidades e o Conselho das Cidades. Na equipe há também profissionais do PCdoB, do PSB e do PPS. De fato, nele não se encontram quadros originários do espectro mais amplo que hoje caracteriza o governo Lula

RBEUR: E quanto ao perfil do profissional que vocês concebem como necessário?

ERMínIA: Para nós a questão ainda não está satisfatoriamente resolvida. Nós, a equipe do MCidades, somos muito poucos, e pensamos que o movimento social que resultou na criação do Ministério são parceiros nas nossas açōes, juntamente com a Caixa Econômica Federal, para realizar um imenso trabalho de capacitação para uma política de desenvolvimento urbano democrática, includente e sustentável. Os movimentos sociais de luta pela reforma urbana criaram um tipo de agente social e um profissional que as escolas, com raras exceçôes, formam. Nós mesmos ainda não temos consolidada essa visão mais holística de amarração das políticas setoriais. Os urbanistas pretensamente têm essa visão, mas têm pensado a cidade de forma muito restrita e dirigida para o mercado. Os regionalistas quase não abordam o intra-urbano. Temos de construir esse novo profissional ao longo do caminho e mudar muitos dos paradigmas. No enfrentamento deste desafio a Anpur sempre foi um componente funda- mental. A Anpur participou de todas as grandes ações, eventos, mobilizações e propostas nessa história da Reforma Urbana. No início da gestão Lula cometemos no MCidades um equívoco ao acreditar que iríamos construir a curto prazo uma imensa rede de capacitadores ou uma Escola das Cidades, assim como o Ministério da Fazenda tem há décadas a Escola Fazendária. No entanto, ficamos tão ocupados em institucionalizar o Ministério, mudar as ações em curso, criar novos programas e rubricas, que a capacitação ficou a cargo de uma equipe composta de uma única pessoa, ou seja, não avançou como imaginamos. Poder executivo é para executar. Todos querem ver resultados a curto prazo: dos agentes do mercado ao movimento social. Corremos muito para apresentar resultados a curto prazo. Se começássemos planejando, para depois executar, não sobreviveríamos. Como primeiras medidas criamos programas novos como parte do Plano Plurianual 2004/2007, mas especialmente nas áreas de Mobilidade e Transporte Urbano, como também alguns Programas Especiais Urbanos (Planejamento, Gestão, Regularização Fundiária, Risco etc). Acima de tudo neste primeiro momento precisávamos reverter o quadro da extrema contenção de recursos. Não conseguimos tudo o que esperávamos, mas avançamos bastante. Do ponto de vista da formulação da PNDU - Política Nacional de Desenvolvimento Urbano, da formulação das políticas setoriais e dos marcos institucionais, andamos em paralelo. A Política Nacional do Saneamento Ambiental, que nos era muito cobrada, foi a primeira a ser levada para a discussão pública. Isso porque o projeto de lei anterior enviado pelo governo FHC não fora aprovado devido a uma ação intensa que teve na Frente Nacional do Saneamento, um dos seus principais opositores. A proposta do presidente Lula era mandar muito rapidamente o PL para o Congresso, mas, diante dos muitos conflitos que surgiram, a estratégia foi mudada e remeteu-se a proposta para as audiências públicas. Foram 11 audiências públicas que o Conselho das Cidades definiu e acompanhou. O projeto de lei da Política Nacional do Saneamento recebeu mais de quatrocentas emendas: é um marco regulatório do saneamento, estabelecendo regras para o setor e recuperando a importância da participação do Estado e do controle social. Ainda como parte desse esforço de institucionalização e formulação da política, definimos também um novo Sistema Nacional de Habitação que 
já foi aprovado no Conselho das Cidades e lançamos as bases para uma Política Nacional de Desenvolvimento Urbano que contém iniciativas também nas áreas da política fundiária e imobiliária, política de planejamento, de transporte e trânsito. Iniciamos programas de capacitação em todas as secretarias. A política de trânsito, por exemplo, é uma política que capacita o tempo todo pois o trânsito é uma grande tragédia, e isso diz respeito ao Ministério das Cidades: são quase 40 mil mortes no trânsito, anuais, e 400 mil acidentes, com um grande número de pessoas incapacitadas para o resto da vida. Estamos colocando em prática a capacitação para o plano diretor participativo. Quer dizer: não é para elaborar qualquer plano diretor, mas sim planos diretores que o Ministério das Cidades, o Conselho das Cidades e a Conferência Nacional das Cidades definem como participativos, includentes e democráticos. Para mudar paradigmas, procedimentos, conceitos etc., precisamos de um grande movimento de capacitação. É inacreditável o grau de carência técnica, de informação ou de administração da maior parte de nossas prefeituras. Um cadastro multifinalitário pode fazer uma grande diferença para a política fiscal, para a política de priorização das açôes (não ouso nem falar em planejamento em alguns casos). Não se trata de uma tarefa federal, mas nacional. O MCidades não pode dar conta dela sozinho. Para tomar um exemplo dramático da necessidade de melhor qualificar o gasto público, vou lembrar que 2/3 do orçamento do Ministério das Cidades em 2005 são formados de emendas parlamentares. Elas se distribuem pelos mais de 5.560 municípios do País. A maior parte dessas emendas ou, $\mathrm{R} \$ 700$ milhōes, estão dirigidos para a infra-estrutura urbana, ou mais exatamente asfalto, em sua maior parte. Como dar maior eficiência, maior racionalidade a estas emendas para que esse gasto seja coerente com as prioridades locais? Capacitar as prefeituras, pactuar com os próprios parlamentares, poderá evitar ou diminuir desperdícios. Nós temos, ao longo de muitos anos, obras construídas que não foram terminadas e quando terminadas não entraram em operação. Agora estamos fazendo este levantamento, que não é banal, e começando um choque de gestão nas localidades que são objeto do investimento fragmentado. Só vamos mudar esse quadro com muita capacitação junto com os governos, nos diversos níveis, e junto com as lideranças sociais, de modo a se obter um controle social maior sobre estes investimentos. O governo federal mesmo, há alguns anos, financiou obras de transporte que não estavam integradas entre si: uma foi dirigida ao governo estadual e outra, ao governo municipal. Neste contexto é que estamos pensando o papel da Anpur. É importante cobrar conhecimento e proposiçōes para essa realidade tão seccionada, dividida, desarticulada em tantas facetas que muitas nos passam despercebidas. Isso tem muito a ver com a pesquisa, o ensino e a extensão. Neste momento de inflexão da nossa política de capacitação, a Anpur e toda entidade que tem potencial para auxiliar nessa transformação podem desempenhar um importante papel em nossa estratégia de pesquisa e de capacitação. Não se pretende violar a autonomia da Universidade, que tem suas próprias demandas de pesquisa, ensino e extensão. Trata-se de pactuar uma agenda para o desenvolvimento urbano clamada pela condição urbana no Brasil.

RBEUR: Este elo fundamental do setor público não entrou ainda na agenda, não se entendeu ainda a relevância desta questão?

ERMínIA: Perfeito, eu ia dizer isso em seguida, não entrou. Há uma invisibilidade da agenda urbana, especialmente entre os economistas, mas não só. Estamos buscando a Enap, que se articula com mais de quarenta escolas de governo em todo o País, a Finep, o CNPq, bem como vamos buscar a Capes e as fundações estaduais para reforçar a nossa agenda.

\section{RBEUR: Tem que ser uma coisa forte.}

ERMínIA: Temos de elaborar coletivamente este documento mostrando que o Ministério das Cidades precisa de pesquisa, precisa de cursos, precisa de capacitação nessas áreas. Necessitamos do aporte de cursos de especialização e de pós-graduação, para fazer a diferença nesse estado de coisas. Para o Ministério fica uma tarefa que a gente não pode delegar: a busca de cooperação entre Ministérios das Cidades, da Ciência e Tecnologia e da Educação, e a definição das necessidades à luz da política nacional de desenvolvimento urbano. Se conseguirmos mobilizar nossa área, com todas as entidades ajudando, participando da elaboração da proposta e influindo com mais força, isso poderá ser viabilizado. 
RbeUR: Passando agora para a politica de desenvolvimento urbano. O Ministério sublinha o fato de que ela não é federal, mas nacional. Qual tem sido a efetividade dos instrumentos de articulação entre Uniāo, Estados e municipios? Quais os meios de "reverter a cultura politica hegemônica" que tende a favorecer uma cidade para poucos, como diz o documento Política Nacional de Desenvolvimento Urbano, publicado em 2004 nos Cadernos MCidades, volume 1?

ERMÍNIA: Combater a especulação, a segregação e a exclusão territorial é uma tarefa longa e tem que ser produto de uma luta social. Instrumentos legais nós temos, embora eles encontrem muita dificuldade na aplicação e sejam dependentes da correlação de forças. A legislação avançada não é suficiente para resolver os problemas da desigualdade, da exclusão social e da segregação. A importância do Estatuto da Cidade e dos Planos Diretores é evidente, mas não suficiente. A luta social e o controle sobre as Câmaras Municipais, na hora em que votam a legislação de uso e ocupação do solo, é fundamental. Como é que você torna coercitivo o controle social? Como usar todas essas ferramentas de participação social, de transparência, que ajudam a negar o modelo de apropriação privada da valorização decorrente do investimento público? Tudo isso diz respeito à autonomia dos entes federativos mas, também, ao pacto federativo. Nós temos enfrentado, muito mais do que eu esperava antes de entrar no Ministério, a discussão sobre o pacto federativo. Eu achava que já conhecia bem a Constituição brasileira. Hoje estou aprendendo que é uma constituição de desenho extremamente complexo, porque ela define autonomia para os três níveis de governo, ao mesmo tempo que define competências comuns, concorrentes e complementares. Então, a Constituição brasileira exige a cooperação, mas tem-se, ao contrário, guerra fiscal num mesmo nível de governo, assim como imensa disputa ou cooptação, dependendo do partido que está aqui ou ali; ou seja, uma cultura difícil de ser superada. Discutindo o sistema de saneamento, por exemplo, todos os assessores jurídicos do governo federal foram unânimes em dizer que não tínhamos condição de cobrar dos municípios certas incumbências na área do saneamento urbano devido à autonomia dada pela Constituição Federal. Uma das questóes discutidas era: como é que vamos levar uma regulação que exige pla- nos, metas, indicadores de desempenho e controle social, se não podemos aplicar isso aos municípios? A nossa saída é a seguinte: quando o governo federal empresta ao município, o município se insere no sistema $\mathrm{e}$, inserindo-se no sistema, tem que cumprir determinadas obrigaçōes e regulaçôes. Veja como a questão não é tão simples como se esperava, nem por meio de uma lei aprovada no Congresso Nacional. A Constituição brasileira pretendeu descentralizar mas, ao mesmo tempo, limitou essa descentralização por meio das competências comuns e concorrentes. Também do ponto de vista econômico existe uma dependência muito grande dos municípios em relação aos demais níveis de governo. Este é um dos temas para a Conferência das Cidades de 2005, o pacto federativo, a gestão compartilhada, a cooperação que se mostra necessária para o desenvolvimento urbano em especial nas regiōes metropolitanas. Precisamos esclarecer as competências dos diversos entes federativos e decidir se há necessidade de novas leis complementares. Precisamos respeitar as competências já definidas claramente, mas não podemos deixar de reconhecer que a situação das gestōes metropolitanas está muito insatisfatória. Todo mundo reconhece isso, inclusive a Comissão de Desenvolvimento Urbano do Congresso Nacional.

Já podemos festejar um grande avanço nas relaçôes federativas que foi a aprovação da lei dos Consórcio Públicos, que vai permitir a gestão cooperativa ou compartilhada de municípios, governos estaduais e União sob a égide do direito público. O impacto sobre a administração pública brasileira dessa conquista ainda não está bem assimilado.

RBEUR: O fundamento deste pensamento holistico estaria centrado nos usos do solo, que concretamente é uma questão da propriedade. Até que ponto essa dimensão estrutura efetivamente os vários braços setoriais do Ministério?

ERMínIA: A definição do uso e da ocupação do solo é tarefa eminentemente municipal, a menos que se trate de área de interesse ambiental, patrimônio nacional ou patrimônio da União. No entanto a PNDU - Política Nacional de Desenvolvimento Urbano tem entre seus eixos estruturantes a terra urbana (ou a questão imobiliária), o financiamento e a estrutura institucional (leis, marcos, regras, competências, quadros etc.). Hoje você não faz uma política de habitação chegar 
nas camadas de baixa renda se o mercado não atingir a classe média. Atualmente o mercado privado atinge cerca de $22 \%$ da população brasileira, grosso modo. Se não inserirmos a classe média no mercado privado vamos continuar gastando subsídio com ela, que tem mais poder para ser ouvida, e ignorando as camadas baixa renda. Em 2000, mais de 80\% dos financiamentos e investimentos federais em habitação - que não são exatamente públicos, porque o FGTS é gerido por um conselho curador do qual o governo participa e preside - estavam dirigidos para o conjunto dos que ganham mais de cinco salários mínimos, onde estão localizados apenas $8 \%$ do déficit habitacional. Este é um problema estrutural do País: um mercado extremamente restrito. $\mathrm{O}$ mercado brasileiro faz um produto de luxo ou, como disse o Nilton Vargas ainda na década de 1970, um artesanato de luxo. Com isto não se resolvia nem o problema da classe média (que também chega a morar em favelas) e muito menos da baixa renda. Temos os primeiros sinais de que estamos mudando essa situação. A aprovação de uma lei enviada ao Congresso Nacional e uma resolução do CMN (ambas em 2004) mudaram a situação do mercado privado: os recursos do SBPE - Sistema Brasileiro de Poupança e Empréstimo que estavam retidos no Banco Central foram desovados para o financiamento privado. Para 2005 um montante equivalente a R\$ 12 bilhões deverá ser aplicado no mercado. Os bancos fazem pressão o tempo todo para diminuir o montante porque estão prevendo que não vão gastar, alegando que "não tem demanda"... Por que não tem demanda? Não tem demanda se mantida a estrutura de mercado como ela se encontra hoje, com esse "artesanato de luxo" para essa faixa de renda com esse preço da terra, com essa margem de lucro e com essa baixa produtividade. É preciso incluir nesse mercado o professor primário e secundário e até o universitário, o policial militar etc. São trabalhadores que têm carteira de trabalho assinada. Os dados mostram que o financiamento privado foi ampliado em $53 \%$ no início de 2005. Avançou por enquanto, mas creio que a mudança do produto assim como o patamar tecnológico da construção devem demorar. Se essa proposta se desenvolver como planejado, esperamos ter o setor produtivo apoiando a reforma fundiária, já que a terra é insumo fundamental para a produção em maior escala. Há muito de utopia nessa coisa mas quem sabe...
Combinada à ampliação do mercado privado estamos colocando em prática uma política para a baixa renda. Os recursos federais públicos e semipúblicos (FGTS e demais fundos) estão sendo dirigidos para as faixas de renda situadas entre zero e cinco salários mínimos (SM), as quais concentram 92\% do déficit habitacional. O orçamento do FGTS prevê mais de R 8 bilhôes para moradia e R $\$ 2,7$ bilhões para saneamento (o orçamento do FAT dispõe de mais R \$ 600 milhões para saneamento). Estamos sendo bem-sucedidos no esforço paulatino de reverter o destino dos recursos que estão em mãos do governo federal para as camadas de de baixa renda. Passamos de menos de 20\% do montante destinado às faixas de até cinco SM em 2000 para uma projeção de $60 \%$ em 2005 . Se todo esse dinheiro for despejado num mercado altamente especulativo, teremos o indesejado resultado de aumentar o preço da terra e da moradia, daí nossa preocupação com a reforma fundiária e imobiliária, daí nossa preocupação com a função social da propriedade prevista no Estatuto da Cidade que, como todos sabem, se realiza por meio do Plano Diretor. A falta de políticas fundiárias, a concentração da propriedade urbana, a tradição patrimonialista que marca também o urbano são as grandes causas de toda a ilegalidade que temos, porque as próprias prefeituras têm dificuldade de chegar na terra, e não lutam por uma legislação, por um zoneamento que permita construir habitação social. A maior parte das prefeituras no Brasil simplesmente não se prepara, não enfrenta essa questão. Governos estaduais, nem se fala. Muitos dos Executivos e Legislativos de municípios de pequeno, médio e até mesmo de grande porte são liderados por proprietários de terra e de imóveis.

RBEUR: Como fica a relação com o mercado no âmbito do novo marco regulatório do saneamento? Na análise do Ministério, visa-se superar problemas de indefinição de competências, ineficiência na gestão e limites do Conselho Monetário Nacional impostos aos empréstimos a órgãos públicos. Esse novo marco será capaz de dar conta dessas três dificuldades? Como ele se situa diante das pressões por um projeto privatizante?

ERMínIA: O principal conflito hoje dá-se em torno à gestão metropolitana. As companhias estaduais se colocam, grande parte delas, contra o projeto porque 
este reconhece a titularidade municipal fixada pela Constituição de 88 . Ele não deixa de reconhecer - e nem pode - a existência e papel das companhias estaduais. Ele reconhece essa possibilidade de compartilhamento do serviço de saneamento. Seria um absurdo, numa mesma bacia ou numa Região Metropolitana, não reconhecer a necessidade desse compartilhamento. Foi forte a crítica das empresas estaduais de saneamento às primeiras versóes do projeto. Ele passou por 11 audiências públicas e recebeu mais de quatrocentas contribuições para mudanças. Esse debate está atrasando seu envio para o Congresso. Mas essa discussão avançou. O principal conflito não está entre estatizar e privatizar, mas entre a titularidade nas Regióes Metropolitanas, o papel do Estado e o papel dos municípios.

Nosso projeto incorpora as PPPs - Parcerias Público-Privadas, mas não deixa a menor dúvida sobre o papel do Estado como o formulador e gestor da política, além de enfatizar instrumentos de planejamento, metas, desempenho, controle social e transparência. Esperamos que o contingenciamento dos empréstimos ao setor público vigente neste começo de 2005 seja transitório.

RBEUR: Não haveria riscos de a responsabilidade municipal favorecer a privatização dos sistemas?

ERMínIA: Na época do Planasa - Plano Nacional de Saneamento e do BNH, era orientação do governo federal, durante o regime militar, centralizar os serviços de saneamento. Essa centralização foi compulsória. Muita prefeitura conseguia recurso para habitação se, em contrapartida, desse a concessão do saneamento para a companhia estadual. Formaram-se grandes empresas públicas e nem todas foram bem administradas. Muitas das companhias estaduais, aliás a maior parte, são ineficientes. Muitas estão falidas. A maior parte dos municípios não tem organismo voltado para o saneamento e muitas das concessões estão em situação irregular. A discussão entre a Assemai - Associação das Empresas Municipais de Saneamento e a Aesb - Associação das Empresas Estaduais ainda não chegou à maior parte da população brasileira. Muito município lutou para ficar com o controle da água e do esgoto no passado, e foi forçado a ceder. Hoje, uma grande parte dos municípios brasileiros ainda tem a titulação da água e do esgoto, outra grande parte tem a titulação só do esgoto, e uma parte maior ainda está numa situação completamente irregular. Cito o exemplo do município de Mesquita na Baixada Fluminense. Nova Iguaçu está com contrato irregular com a Cedae - Companhia de Águas e Esgotos do Rio de Janeiro. Mesquita foi desmembrada de Nova Iguaçu há quatro anos. Mesquita está com a Cedae fornecendo água de forma insatisfatória. Não há nenhum contrato entre eles e o município não sabe bem o que fazer diante desse quadro, mas está buscando alternativas, assim como todos os municípios da Baixada Fluminense que estão descontentes com a situação. Estamos, em grande parte do Brasil, numa situação de caos, sem regras ou base jurídica clara. Não será a competência estadual ou municipal que deverá facilitar a privatização.

RbeUR: Passando a uma outra área de indagaçôes: com respeito à articulação com a sociedade civil organizada, através dos Conselhos e das Conferências, como se tem dado essa relação?

ERMínia: O Ministério das Cidades é fruto deste movimento social que lutou muito tempo para incluir a questão urbana na agenda nacional. A proposta de um Ministério das Cidades seria completamente diferente sem a participação social, como mostram os órgãos que nos antecederam. O que impede que o MCidades se transforme em um balcão de negociação de emendas apenas é a orientação do ministro e da sua equipe em parceria com os atores que constituem a sociedade organizada. Hoje, 2/3 do orçamento do Ministério é composto por emendas. Se algum ministro quisesse projeção política por meio da aplicação de emendas, encontraria no Ministério das Cidades uma situação propícia. Para que o Ministério não seja reduzido a um balcão, ele tem que ser o coordenador de uma política nacional. Essa visão do Ministério de que a questão fundiária não pode ser desligada da questão do financiamento também pode ser abandonada rapidamente, porque em nível federal não há formas evidentes de fazer uma vinculação muito profunda entre essas questôes: a fundiária, a financeira e também a institucional. Apenas por meio do financiamento que inclua no contrato a etapa do DI - Desenvolvimento Institucional podemos tornar compulsório um plano local, elaboração de cadastros, bem como a participação social e o 
acompanhamento pós-ocupação, como faz o Programa Habitar Brasil de urbanização de favelas. Por meio dele muitos municípios começam a se conhecer melhor, por exemplo quantas famílias moram ilegalmente, quantas famílias moram em favelas, em loteamentos ilegais ou em áreas de risco.

Essa política, que faz avançar a administração, a participação e a cidadania, deve ser garantida pelo controle social que no MCidades é exercido especialmente pelo Conselho das Cidades.

Nós realizamos a I Conferência Nacional das Cidades atingindo mais de 3.400 municípios. Eu duvidava que chegássemos a quinhentos municípios. $\mathrm{O}$ ministro Olívio Dutra falou: "vamos chegar a mil, dois mil". O que aconteceu foi que o Ministério não realizou isso sozinho, e nem poderia. Foi a mobilização social, esse braço organizado da política urbana que saiu construindo literalmente as conferências municipais e estaduais. Os governos estaduais e municipais foram os promotores do evento, mas os atores organizados foram fundamentais. Não conseguíamos nem mandar gente do Ministério para todas as reuniōes. Ficamos assoberbados com tantas conferências municipais, regionais, estaduais ou dos segmentos como de arquitetos, de engenheiros, reunião de universitários, de centros de pesquisa e de movimentos sociais que estavam discutindo o que foi colocado na I Conferência - os princípios, diretrizes e prioridades da política urbana. Foi uma construção árdua, mas acho que foi realmente um mutirão, um esforço coletivo, e por isso ela foi tão bem-sucedida.

Nós tivemos dificuldade de pagar a instalação da Conferência para tanta gente -2.800 delegados. Estavam presentes diretores de bancos, que sentaram ao lado de lideranças sociais de favelas e assim por diante. Não é pouco para a história do Brasil, um país de tanta desigualdade e discriminação. Então criamos o Conselho das Cidades e quatro Câmaras Técnicas que começaram a funcionar a partir de 2004.

O Conselho das Cidades aprovou uma campanha para o plano diretor participativo que o Ministério vai levar às ruas durante este ano. Aprovou ainda o Sistema Nacional de Habitação, a Política Nacional do Saneamento Ambiental, a Política Nacional de Trânsito, diretrizes da Política de Mobilidade e Transporte e revisão da Lei de Parcelamento do Solo, Lei 6.766. Discutiu-se o Programa Brasil Acessível que inclui duas leis que regulamentamos e uma rede com setor empresarial de produtores de veículos para, dentro do prazo previsto pela lei, adequarmos os ônibus brasileiros e as cidades brasileiras à mobilidade dos idosos e portadores de deficiência. O Conselho aprovou também o programa de regularização fundiária que não existia no governo federal, e que começou a deslanchar em meados do ano passado. É um programa cuja implementação não depende apenas do Ministério, que tem na prefeitura seu agente central e que depende também dos Cartórios de Registro de Imóvel, do Judiciário e do Ministério Público. A secretária de Programas Urbanos Raquel Rolnik acertou um convênio por meio do qual os cartórios vão fazer registro gratuito quando se tratar de moradia de interesse social. O Conselho das Cidades agora criou um grupo para fazer acompanhamento do orçamento do Ministério das Cidades e outro grupo para ajudar a organizar a II Conferência Nacional. No momento estamos discutindo um texto básico para a próxima Conferência.

Infelizmente a Anpur ficou fora do Conselho na condição de titular, o que é lamentável, porque a Anpur tem de fato um acúmulo que é fundamental para aquele Conselho. Vamos ver se este ano as negociações políticas para a renovação do Conselho permitem que essa ausência seja superada.

RBeur: Do ponto de vista da democratização da dinâmica decisória, o que é que esses espaços conseguem incorporar em seu âmbito, considerado o alcance da crise urbana, da fragmentação e dos conflitos urbanos? A questão da segregação socioespacial pode vir a ser, depois de se enfrentar as questôes mais imediatas, discutida e enfrentada?

ERMínIA: A questão da segregação é um tema constante no Conselho. Quando se discute mobilidade, transporte e acessibilidade o que está em pauta é o direito à cidade. Com o saneamento idem, trata-se dos direitos da população excluída. Quando se discute habitação ou programas urbanos, esse tema vem à tona a todo o momento. A questão fundiária, como já foi destacado, não é uma atribuição direta do Executivo federal senão sob alguns aspectos específicos. A campanha do Plano Diretor pretende fazer com que os Planos apontem onde vai ter moradia social no interior das áreas urbanizadas. Estamos colocando a questão nesses termos bem simples. Onde vai morar a maior parte da população 
que hoje não tem lugar na cidade formal, legal e urbanizada? Ela não pode ser ignorada.

RBEUR: Não caberia pensar um curso em que se projetasse a cidade democrática?

ERmínia: O IAB [Instituto de Arquitetos do Brasil], em parceria com o Ministério das Cidades, vai conduzir uma campanha pelo Direito à Arquitetura para Todos. Estamos pensando no edifício e no desenho urbano, especialmente na moradia chamada impropriamente de social. A Federação Nacional dos Arquitetos vai conduzir uma campanha pelo direito à cidade e ao urbanismo e também pela universalização da Assistência Técnica também para a moradia social. Essas campanhas envolverão os Creas, o Confea, o FNEA - os estudantes de Arquitetura -, a Abea. Além dos engenheiros e arquitetos, precisamos chegar aos advogados e demais profissionais para as assessorias técnicas. Não se trata de uma questão corporativa. Trata-se do direito à cidade e do direito à moradia. Mas precisamos atingir nossas instituições formadoras de profissionais e pesquisadoras...

RBEUR: A articulação entre luta social e capacitação numa visão mais abrangente do que a corporativa em relação ao direito à cidade tem se manifestado recentemente?

ERMínIA: Sim, tem. O discurso atual do pessoal dos transportes é emocionante se levarmos em conta que até há pouco tempo o campo foi dominado pela matriz corporativa daqueles que chamávamos de "transporteiros". Eles pensam de forma holística. Ainda temos muito resquício da matriz antiga sem dúvida, mas a nova semente é forte. A ANTP vem, há muitos anos, difundindo a relação entre transporte e uso do solo, a qual dominou, aliás, muitos dos CIAMs. Na maior parte das cidades brasileiras, mas em especial no CentroOeste, Sul de Minas, interior de São Paulo e Norte do Paraná, o absurdo número de lotes vazios constitui um problema muito grave para o custo da infra-estrutura, em especial aquela ligada aos transportes. A desregulamentação dos serviços públicos, os recuos dos investimentos e a tendência de privatização, dominantes nos anos 90, atingem, de modo geral, todas as áreas das quais o MCidades se ocupa. Relacionar esses problemas com a exclusão territorial nos leva a entender as causas dos dramas que nossas cidades vivem, no entanto a formação profissional ainda é compartimentada e elitista, ou seja, não busca soluçôes para a maioria que está excluída.

RBEUR: Como esse debate está se organizando com vistas à próxima Conferência das Cidades?

ERmínia: Lançamos oito cadernos da Política Nacional de Desenvolvimento Urbano. O que eles têm de bom é o acúmulo de muitos anos de tudo o que fizemos e que avançou como política institucional do MCidades, respeitando, obviamente, os limites legais e ações em andamento. Os cadernos foram redigidos um tanto prematuramente, sem que todos os estudos estivessem concluídos, e lançados no final de 2004. Como o tema da reforma ministerial é recorrente estamos sempre tentando consolidar o estágio presente para, se houver substituição da equipe do MCidades, deixarmos algo de pactuado e consolidado. Entendemos que a PNDU será reescrita e complementada após a Conferência de 2005.

Para discutirmos a PNDU na próxima Conferência o Conselho das Cidades elegeu quatro grandes temas gerais e quatro campanhas de temas mais específicos. Os temas gerais são os seguintes:

1 Participação social na política de desenvolvimento urbano nos três níveis de governo.

2 Pacto federativo ou cooperação intergovernamental para o desenvolvimento urbano.

3 Financiamento do desenvolvimento urbano.

4 Prioridades da política urbano/regional e metropolitana (nesse caso teremos em mãos estudos que estão sendo desenvolvidos em várias universidades federais).

As campanhas são as seguintes:

a Plano Diretor Participativo - em que a questão fundiária e imobiliária terá centralidade com a aplicação do Estatuto da Cidade e a função social da propriedade. Sempre é importante lembrar que entre intenção e fato há uma profunda distância, por isso teremos de trabalhar muito para não termos novamente uma indústria de PDs que fazem mais mal do que bem, como acontece freqüentemente com legislações urbanísticas que reforçam a segregação e a ilegalidade. Pretendemos usar um decálogo, que na verdade são 12 pontos, como vacina ao PD tecnocrático e burocrático. 
b A aprovação do PL da Política do Saneamento Ambiental - que pretende fornecer regras e dar um marco institucional para uma área que está muito desregulada.

c A aprovação do PL do Fundo Nacional de Habitação de Interesse Social - que está há quase 13 anos no Congresso Nacional e que no momento está no Senado, após aprovação pela Câmara Federal.

$\mathrm{d}$ Acessibilidade e mobilidade - campanha por uma cidade mais acessível para os idosos e pessoas com deficiência.

Muitos dos participantes do Conselho das Cidades defendem institucionalização da participação social na política urbana ou mesmo um sistema à semelhança do SUS. Todos concordam entretanto que temos muito pouco acúmulo no País para definir tal estrutura neste ano sem uma discussão ampla, abrangente e democrática.

RBEUR: E quanto a isto, como fica a relação do Ministério das Cidades com os outros ministérios mas, sobretudo com aquilo que podermos chamar de ministério do território, no caso seria esse Ministério da Integração Nacional?

ERMÍNIA: Essa é uma relação que estamos construindo. Foi lançado um Plano Nacional de Desenvolvimento Regional e nós estamos perfeitamente afinados com aquelas linhas gerais e diretrizes, já que a professora Tânia Bacelar participou daquela construção e hoje nos assessora na proposta da política urbana/regional. Como parte dessa política foi criada uma Câmara Interministerial de Desenvolvimento Regional e essa câmara criou alguns grupos de trabalho interministeriais visando a integração das ações federais e algumas regiôes. $\mathrm{O}$ MCidades ganhou a coordenação de um GT que trata das regiōes metropolitanas. Como nossas pernas são mais curtas do que nossas tarefas, não demos ainda a devida velocidade ao assunto que é central. A questão metropolitana é especialmente delicada devido às competências federativas. O quadro atual da gestão metropolitana não é nada satisfatório, porém quando o governo federal toca no assunto há reações de um ou outro governo estadual contra o que é interpretado como uma intervenção indevida. Como o problema é pauta da Conferência Nacional deste ano e estamos desenvolvendo diversos estudos e ações visando um pacto federativo, esperamos avançar com esse assunto tanto em relação à própria União quanto na relação federativa. Nesse sentido temos atuado de forma muito cooperativa com a SAF - Secretaria de Assuntos Federativos, que pertence à Secretaria de Coordenação Política.

É preciso reconhecer, no entanto, que há muito a fazer nessa questão territorial, pois vários são os ministérios que elegem regiōes prioritárias para intervenção, como é o caso da Região do Arco do Desmatamento, na Amazônia, e a Região do Pantanal (ambas de interesse do MMA), Regiōes de Fronteira (MRE, MIN e Defesa), Região do Semi-Árido (Intermini) e Região do Vale do Jequitinhonha (MIN, MMA, MDS e outros), apenas para lembrar alguns. Como há cidades em todos eles, nós ficamos um pouco assoberbados e sem poder responder satisfatoriamente a todas as demandas.

RBEUR: Você poderia falar um pouco dos constrangimentos de ordem macroeconômica, que certamente, nós sabemos, limitam a ação transformadora: há sinais de percepção no interior do Estado dessa forte associação entre a crise urbana e as grandes escolhas macroeconômicas?

ERMÍNIA: Eu tenho me recusado a fazer comentários sobre a política macroeconômica, como vocês sabem. Sou parte do governo e espero por mudanças que nos permitam enfrentar os problemas considerando a escala que eles apresentam. Estou sempre procurando entender por onde passa a continuidade e as mudanças. $\mathrm{O}$ que as determina. Quero apenas comentar aqui a constatação das dificuldades dos economistas enxergarem a questão urbana. Economistas em todos os níveis, não só os da máquina do governo federal. No seminário que lançou a Proposta Nacional de Desenvolvimento Urbano, insistimos na questão da relação entre desenvolvimento urbano e desenvolvimento. Ficamos impressionados como isso não é visto. Mesmo nos abundantes relatórios internacionais sobre a pobreza a pouca importância dada às cidades é notável, em especial à política fundiária e imobiliária.

RBEUR: Há uma alienação territorial incluindo as metrópoles? Abstraem-se os fluxos, imaginando-se a coisa econômica desconectada da questão territorial?

ERMínIA: Sem dúvida, essa constatação é notável. Onde foram parar as heranças de Caio Prado e Celso Furtado? 
RbeUR: Há uma preocupação, nos textos da Política $\mathrm{Na}$ cional de Desenvolvimento Urbano, com a menção às perdas econômicas do mal desenvolvimento?

ERMínia: Percebo que, na lógica prevalecente, não é o prejuízo econômico que mais conta, mas o financeiro. Póe-se dinheiro na obra desde que a rentabilidade daquele dinheiro que você vai investir for maior do que a de outro negócio ou se o retorno medido pela rentabilidade financeira for maior. Essa é a lógica utilizada para aprovar projetos que compóem as exceções em relação ao superávit primário. É difícil ser ouvido a partir de outro lógica. Fizemos uma proposta para a área de transporte coletivo para compor os famosos "projetospilotos" negociados com o FMI. Mostramos como um corredor de ônibus permite economia de combustível, rapidez do tráfego, pois retira automóveis de circulação, diminuição de horas perdidas, economia de insumos como pneus etc., redução da poluição, redução de acidentes com mortos e feridos etc. Calculamos o valor de tudo isso. $\mathrm{O}$ financiamento do governo federal seria condicionado a uma política de integração dos transportes, o que levaria e uma economia maior. Mas a lógica do julgamento não é econômica mas financeira, foi o que percebi com meus parcos conhecimentos na área.

RBEUR: Na discussão sobre cidade e desenvolvimento regional, os documentos do Ministério falam em "tentar favorecer novas centralidades", dada a nova configuração da rede urbana.

ERMínIA: Se você pegar as políticas setoriais e mesmo a política intra-urbana holística, no Ministério, nós estamos bem preparados. Temos experiência de reflexão, de administração e de militância. Se você pegar a questão do território nacional - eu não sei se chamamos isso de questão regional - é diferente. O debate não está suficientemente maduro e volta e meia retornamos para algumas teses antigas como foi o Programa de Cidades Médias dos anos 70. O PNUD divulgou há pouco o que deveria ser prioridade - seiscentos municípios carentes. Para buscar as prioridades da política urbana partindo de uma visão territorial, estamos construindo uma tipologia de cidades que vai, evidentemente, levar em conta a dinâmica regional. Numa primeira opção, podemos decidir fortalecer os pólos médios regionais, especialmente nas áreas dinâmicas no Brasil, ou inter- vir onde o Brasil está crescendo muito, Norte, CentroOeste e alguns lugares do Leste. Numa segunda escolha, teríamos de nos concentrar nas regióes metropolitanas porque $80 \%$ das favelas estão ali localizadas. Por fim, outros nos assinalam os pequenos municípios de base rural e a necessidade de neles desenvolver consórcios ou associações de municípios para qualificar e segurar os jovens, dar perspectiva e condição econômica e social para estes jovens. Eu estou olhando isso com a tranqüilidade de que vamos, exatamente, ter um amplo debate com propostas que não são simples, como revela a história geopolítica do Brasil.

RbeUR: Na experiência dos eixos do Avança Brasil, esqueceram as cidades. Em princípio, não seria preciso cidade nenhuma para a soja, mas ao construir e asfaltar vias para escoar a soja poderão aparecer favelōes nas beiras de estradas. Nesse sentido, falamos aqui da necessidade de capacitação, da passagem ao conhecimento. Mas, onde racionalidades distintas encontram-se em jogo, caberia talvez pensar em espaços de persuasão. Haveria que se construir um arrazoado para a interlocução com fabricantes de emendas que querem o bem dessas populaçôes que representam mas não têm a noção da relatividade daquela decisão no âmbito do desafio de se fazer politicas mais articuladas, mais eficazes.

ERMínIA: Aí tratar-se-ia de conscientização, um trabalho mais pedagógico do que propriamente preparar quadros. Vejo que na nossa ação a comunicação é fundamental. Ocupar o espaço político é o que me preocupa o tempo todo. Como é que nós entramos na agenda política, como ganhamos espaço político, poder político, legitimidade, importância nesse quadro de invisibilidade do território e das cidades. Quando a gente discute no Ministério constatamos um mundo de boas intenções mas freqüentemente os recursos das emendas tomam caminhos fragmentados.

De alguma maneira, na agenda encontra-se até a luta para garantir a existência do Ministério sem tornar-se um balcão, com a sua missão de coordenar este esforço nacional. Estamos conquistando muitos prefeitos. O Ministério das Cidades está representando uma proposta. Essa proposta conquistou muitos cargos municipais a partir da última eleição para prefeitos, no final de 2004. São pessoas que passaram pelos nossos cursos (das nossas universidades), passaram pelos nos- 
sos movimentos, pelas nossas mobilizações, pelos nossos eventos, que fizeram teses com denúncias ou com busca de saídas. Tudo isso estava muito pulverizado apesar do esforço do movimento de reforma urbana. $\mathrm{O}$ que eu sinto é que estamos avançando muito rapidamente nesses dois anos, se olharmos todo o tempo de caminhada. Por quê? Porque sempre falamos que o Estado tinha que assumir o seu papel de regulador. Nós temos muita dificuldade ainda de entrar na agenda do Congresso. Tivemos sim uma troca intensa com a Comissão de Desenvolvimento Urbano da Câmara Federal. Avançamos em nossas relações com a equipe que coordena os trabalhos e com vários parlamentares.

Entre suas cinco prioridades para o orçamento de 2005 a Comissão elegeu quatro que eram coincidentes com as prioridades do Ministério. Quando chegou no orçamento final, caíram as quatro prioridades e permaneceu uma: exatamente a que diz respeito à infra-estrutura, que redunda em asfalto, especialmente. $\mathrm{O}$ que eu depreendo daí? No Congresso Nacional, externamente à Comissão de Desenvolvimento Urbano, nós ainda não somos agentes. Nós o somos, na medida em que o Ministério se tornou um espaço de cobiça na reforma ministerial mas especialmente porque concentra muitas emendas. Em relação aos economistas já comentei nossa invisibilidade. Em relação à mídia, houve um avanço, ainda que absolutamente insatisfatório - a Folha de S. Paulo criou o caderno "Cidades", depois o extinguiu ou transformou-o para caderno "Cotidiano". Raramente você vê notícias sobre cidades nos cadernos de política nacional. $\mathrm{O}$ assunto vai para o caderno de política local. Mas acho que estamos avançando em visibilidade, principalmente com a criação do Ministério, do Conselho e das Conferências. Alguns prefeitos estão percebendo isso. Algumas entidades profissionais e sociais estão defendendo a proposta do Ministério como se fosse uma coisa delas. Por exemplo, eu não pude ir no Encontro do Confea em São Luís (houve reuniōes dos Creas no País inteiro, sobre sustentabilidade urbana; fui em várias, a discussão foi importantíssima e ganhamos muita gente para o debate democrático), mas percebi, lendo o jornal, que um companheiro, que é do Conselho das Cidades, assumiu as propostas do Conselho e do Ministério e divulgou nossas políticas em elaboração. Foi maravilhoso. Tem alguém lá que defendeu nossa proposta. Não digo que seja interessante essa identidade entre papel da sociedade e papel do governo, não é isso, falo do projeto em si. É preciso lembrar que, como governo, nós apanhamos também.

RBEUR: O que o Ministério entende poder ser a contribuição da Anpur?

ERMínIA: Em relação à Anpur, acho que ela deveria entrar no Conselho das Cidades, a partir da Conferência de 2005. Temos tanto a discussão da proposta que a Tânia Bacelar vai trazer envolvendo uma Política Territorial Urbana para o País, como a proposta de Política de Pesquisa, Tecnologia e Capacitação. Nessa, a Anpur é o principal interlocutor porque não poderemos fazer essa capacitação só pela via das ONGs.

RBEUR: A agenda de pesquisa deve ser conversada de ministério para ministério, de ministro para ministro, envolvendo ciência e tecnologia. A conjuntura não estaria a favorecer uma mobilização do movimento social e intelectual em consonância com a dinâmica desse Ministério?

ERMínIA: Se vocês estivessem no Conselho das Cidades, a coisa já seria completamente diferente. Necessitamos de um primeiro documento para discutir ciência, tecnologia, pesquisa e capacitação, definindo os interlocutores, os assuntos, os financiadores, e para quem a gente se dirige.

Rbeur: Para concluir, você pode dizer que há espaço para uma ação política que leve a algum tipo de transformação? A despeito de constrangimentos de ordem econômica e da carência de recursos, há processos que valem a pena ser desenvolvidos?

ERMÍNIA: Sou uma pessoa muito crítica. Já abandonei muito lugar porque eu não via essa mudança, esse avanço e esse crescimento. O ministro Olívio Dutra é um uma pessoa voltada para a o interesse público. Ele tem essa postura dedicada para a organização popular, social, democrática e transparente. Eu acredito que nossa geração vai realizar a utopia de criar uma Política Nacional de Desenvolvimento Urbano democrática, solidária, com todos os valores que a gente sempre quis. Há garantias de que ela seja sustentável? A única forma de garantir sua sustentabilidade - embora sua institucionalização seja importante - é a luta social. Pois mudança cultural é o que importa. 